\title{
Determinação altimétrica através do sistema de posicionamento global
}

\author{
Altimetric determination thru the global positioning system
}

Cláudia Weber Corseuil ${ }^{1}$ Adroaldo Dias Robaina ${ }^{2}$

\section{RESUMO}

Este estudo tem por objetivo verificar a influência do tempo de coleta de dados com receptores GPS nas determinações altimétricas. O levantamento altimétrico é realizado através do método de posicionamento relativo estático, utilizando dois receptores GPS de uma freqüencia, em diferentes tempos de ocupação (30, 15, 10 e 5 minutos) com uma taxa de gravação de dois segundos. As altitudes obtidas com receptores GPS são comparadas com as altitudes determinadas por nivelamento trigonométrico com Estação Total. Os resultados mostraram que os tempos de ocupação menores que 30 minutos $(15,10$ e 5 minutos) também são adequados para a obtenção de diferenças centimétricas nas altitudes analisadas. Mesmo considerando a precisão dos métodos topográficos convencionais, este estudo demonstra a possibilidade da utilização do Sistema de Posicionamento Global (GPS) de forma precisa nos levantamentos altimétricos, desde que se efetue a modelagem da ondulação geoidal.

Palavras-chave: altimetria, sistema GPS, método relativo estático.

\section{ABSTRACT}

This study aims at the influence on the data acquisition with GPS receivers in altimetric determination. The altimetric survey is carried out through the method of static relative thread, using two GPS receivers of one frequency, at different times of occupation (30, 15, 10, 5 minutes), with a recording level of two seconds. The altitudes obtained with receivers GPS are compared with the altitudes determined by trigonometrical leveling with Total Station. The results showed that the periods of occupation lower than 30 minutes $(15,10$ and 5 minutes) are also appropriated to obtain the centimetric differences for the analyzed altitudes. Considering the accuracy of the conventional topographical methods, this study demonstrates the possibility of the precise use of the Global
Positioning System (GPS) in altimetric surveys, if modeling of the geoidal undulation is also used.

Key words: altimetry, system GPS, relative static method.

\section{INTRODUÇÃO}

O Sistema de Posicionamento Global (GPS) vem sendo muito utilizado nos levantamentos geodésicos para fins topográficos, pois oferece uma série de vantagens em relação aos métodos convencionais usados em Topografia. Estas vantagens estão relacionadas à eficiência na coleta $\mathrm{e}$ automação dos dados, à dispensa de intervisibilidade entre vértices (pontos), ao transporte simultâneo de coordenadas tridimensionais ( $\mathrm{x}, \mathrm{y}$ e $\mathrm{z}$ ), em qualquer hora do dia e sob qualquer condição atmosférica.

Com o crescente interesse pela utilização do GPS para medições geodésicas de curta distância, foram desenvolvidos vários métodos de posicionamento, dentre os quais se destaca o método relativo estático. Este método consiste em posicionar um receptor GPS em um ponto de coordenadas conhecidas e um outro receptor no ponto no qual deseja determinar as suas coordenadas. Através do rastreamento simultâneo de satélites do sistema GPS por um intervalo de tempo recomendado (aproximadamente 1 hora), são calculadas as coordenadas tridimensionais (latitude, longitude e altitude) do ponto desconhecido. A principal vantagem do método é a sua precisão, quando comparado com

\footnotetext{
${ }^{1}$ Engenheiro Florestal, Doutorando em Agronomia, Departamento de Engenharia Rural, FCA/UNESP Fazenda Experimental Lajeado, 18603-970, Botucatu-SP. Email:. cwcorseuil@fca.unesp.br. Autor para correspondência.

${ }^{2}$ Engenheiro Agrônomo, Professor Titular, Departamento de Engenharia Rural, Centro de Ciências Rurais, Universidade Federal de Santa Maria. Email: arobaina@ccr.ufsm.br.
} 
outros métodos de posicionamento e a sua principal desvantagem é o elevado tempo de permanência recomendado para a coleta de dados. Para os levantamentos topográficos, surge a questão de qual é o tempo necessário de permanência ou ocupação no ponto com receptores GPS de uma freqüência $(1.575,420 \mathrm{MHz})$, para se obter a precisão nos levantamentos deste tipo, que possa substituir, adequadamente, as técnicas convencionais utilizadas em Topografia.

As determinações altimétricas feitas a partir do sistema GPS apresentam certas restrições, uma vez que as altitudes obtidas são referenciadas ao elipsóide WGS-84 (World Geodetic System 1984). Segundo TEIXEIRA et al. (2000), as altitudes referidas ao WGS84 (altitudes geométricas) não têm um significado físico e sim geométrico o que vem a ser uma limitação para aplicações nas Engenharias. Porém, esta limitação pode ser eliminada usando-se altitudes relacionadas ao campo gravitacional da Terra ou superfície geoidal, ou seja, as altitudes ortométricas $(\mathrm{H})$. Neste sentido, as altitudes geométricas $(\mathrm{h})$ podem ser transformadas em ortométricas $(\mathrm{H})$, através do conhecimento da ondulação geoidal (N) do local. Segundo MEREGE FILHO (1993), para determinação das altitudes ortométricas a partir das geométricas, é necessário que se conheça a diferença entre elas. Esta diferença é denominada de ondulação geoidal $(\mathrm{N})$ e pode ser determinada pela equação: $\mathrm{H}=\mathrm{h}-\mathrm{N}$

A determinação da ondulação geoidal (N) de uma certa região pode ser feita através de determinações astronômicas, gravimetria (medições de gravidade na superfície terrestre) e por modelamento matemático para fins de mapeamento geoidal ou modelagem geoidal (interpolação geoidal). Porém, de acordo com BERALDO \& SOARES (1995), o modelamento matemático é o mais utilizado para transformação das altitudes geométricas (h) em ortométricas $(\mathrm{H})$, uma vez que os outros métodos são muito demorados, complexos e requerem alta precisão.

Neste sentido, este trabalho pauta-se numa metodologia para a utilização da tecnologia GPS na determinação de altitudes ortométricas a partir das altitudes geométricas obtidas com GPS, com precisão adequada aos levantamentos topográficos em um curto intervalo de tempo de ocupação dos pontos de uma poligonal.

Assim, o objetivo deste estudo foi verificar a influência dos diferentes tempos de coleta de dados (tempo de ocupação e de permanência) nos pontos, com uma taxa de gravação de dois segundos, para a determinação de altitudes ortométricas $(\mathrm{H})$ a partir das altitudes geométricas (h) utilizando-se receptores GPS de uma freqüência.

\section{MATERIAL E MÉTODOS}

O trabalho foi realizado no Campus da Universidade Federal de Santa Maria (RS) numa área localizada entre as coordenadas geográficas $29^{\circ} 42^{\prime}$ 50 " e 290 43' 09" de latitude Sul, $53^{\circ} 42^{\prime}$ ' $25^{\prime}$ " e $53^{\circ} 42^{\prime}$ 50 " de longitude Oeste e altitude ortométrica média de $100 \mathrm{~m}$, aproximadamente. A área em estudo consiste em um polígono fechado com 5 pontos, selecionados de uma poligonal maior, implantada em 1999 pelo Professor Gomercindo G. M. Marques do departamento de Engenharia Rural da UFSM. Os pontos topográficos dos vértices da poligonal possuem coordenadas altimétricas calculadas analiticamente, a partir das medidas dos ângulos verticais e das distâncias entre estações obtidas por nivelamento trigonométrico, utilizando uma Estação Total, marca SOKKIA, com precisão de $5 \mathrm{~mm} \pm 3 \mathrm{ppm} x$ D. O critério de seleção dos pontos foi estabelecido de maneira a representar uma situação real de levantamento no campo.

Foi realizado um outro nivelamento trigonométrico com Estação Total, de modo a referenciar a altitude da antena do receptor base (Ponto B) e os pontos da poligonal teste (PGT), a uma Referência de Nível $(\mathrm{RN})$. Esta $\mathrm{RN}$ pertencente à Rede de Nivelamento Brasileira, identificada pela RN 1792H, materializada por um marco de concreto localizado próximo a entrada principal da UFSM, cuja altitude ortométrica $(\mathrm{H})$ é de $85,758 \mathrm{~m}$.

A partir das altitudes geométricas (h) obtidas com os receptores GPS nos 5 pontos da poligonal teste e da altitude geométrica da base (Ponto B), foi realizado um ajustamento das medidas obtidas com a finalidade de obter as ondulações geoidais médias $(\mathrm{N})$ da região em estudo. A altitude ortométrica $(\mathrm{H})$, a altitude geométrica (h) e a ondulação geoidal (N) relacionam-se da equação: $\mathrm{H}=\mathrm{h}-\mathrm{N}$

No levantamento dos dados, foram utilizados dois receptores GPS de freqüência 1.575,420 $\mathrm{MHz}$ e modelos diferentes para a estação base e para os pontos da poligonal. No ponto de coordenadas conhecidas ou estação base (Ponto B), foi utilizado um receptor GPS da marca TOPCON, modelo GP-R1, com 12 canais paralelos e independentes para recepção dos sinais dos satélites, cuja precisão alcançada no pós-processamento dos dados é de $5 \mathrm{~mm} \pm 2 \mathrm{ppm}$ (TOPCON AMERICA CORPORATION, 1993). Nos pontos da poligonal (P1, P2, P3, P4 e P5), utilizou-se 
um receptor da marca SOKKIA, modelo GSS1A, com 8 canais paralelos e independentes. No pósprocessamento dos dados, a precisão fornecida é de $5 \mathrm{~mm} \pm 1 \mathrm{ppm}$ (SOKKIA, 1999a). A antena da estação base permaneceu fixa no ponto de coordenadas conhecidas (Ponto B) e a outra foi instalada em cada ponto da poligonal (P1, P2, P3, P4 e P5).

O processamento dos dados foi feito no programa computacional SPECTRUM SURVEY, versão 1.20 da SOKKIA. Os dados coletados pelo receptor base foram convertidos para o formato RINEX (Receiver Independent Exchange), que é um formato universal utilizado para entrada de dados na maioria dos programas computacionais de processamento de dados obtidos com receptores GPS. Essa conversão foi feita no módulo ASHTORIN do programa GPPS da ASHTECH. Esse procedimento foi necessário devido ao fato de os arquivos gerados pelo receptor base não serem compatíveis com o programa SPECTRUM $S U R V E Y$. A utilização desse programa justifica-se pela facilidade de manuseio dos dados.

No presente estudo, foi utilizado o posicionamento relativo estático, no qual as coordenadas de um ponto desconhecido são determinadas em relação a um ponto de coordenadas conhecidas (estação base). A antena do receptor base foi instalada no Ponto B (estação base), localizado no prédio 42 do Centro de Ciências Rurais (CCR) da UFSM, com coordenadas geográficas $29^{\circ} 43^{\prime}$ 04,9200" $\mathrm{S}$ e $53^{\circ} 43^{\prime} 00,4300^{\prime}$ 'W e altura geométrica de 129,0373 $\mathrm{m}$. Esse ponto fica a uma distância inferior a $1 \mathrm{~km}$ dos pontos da poligonal (P1, P2, P3, P4 e P5) e livre de obstáculos que possam interferir na recepção dos sinais dos satélites. O receptor do Ponto B foi configurado para coletar os dados com uma taxa de gravação de 2 s e ângulo de corte de $10^{\circ}$, permanecendo ligado durante toda a sessão de observação. O receptor utilizado nos pontos da poligonal recebeu a mesma configuração do receptor instalado no Ponto $\mathrm{B}$, no que se refere à taxa de gravação de $2 \mathrm{~s}$, diferindo quanto ao ângulo de corte utilizado, que foi de $15^{\circ}$. A antena desse receptor foi instalada sobre os pontos da poligonal a uma altura de $2,500 \mathrm{~m}$, controlada por um dispositivo de regulagem de altura e devidamente fixada a um suporte bipé dotado de um nível de bolha, para permitir a verticalização da antena sobre o ponto topográfico escolhido.

\section{Tempo de ocupação nos pontos de coleta de dados}

Foram realizadas sessões de observações com um tempo de ocupação de 30 minutos em cada ponto e uma taxa de gravação dos dados de $2 \mathrm{~s}$. O tempo de ocupação foi escolhido de acordo com as orientações de HOFMANN-WELLENHOF et al. (1997), que fornece o tempo de duração das sessões em função da distância entre o receptor colocado na base e o receptor posicionado no ponto a determinar.

Os arquivos de 30 minutos de observação, que correspondem a 900 épocas registradas pelo receptor na taxa de gravação de $2 \mathrm{~s}$, foram fracionados em arquivos de 15,10 e 5 minutos, correspondendo a 450,300 e 150 épocas, respectivamente.

\section{Processamento dos dados}

Os dados coletados com os receptores, em cada tempo de ocupação, foram processados no programa SPECTRUM SURVEY 1.20, utilizando-se a equação da dupla-diferença de fase (SOKKIA 1999b), para determinação das coordenadas geocêntricas (coordenadas determinadas em relação ao centro de massa da Terra) dos pontos da poligonal. As informações solicitadas para o processamento dos dados foram: as coordenadas geográficas do ponto B (latitude, longitude e altura geométrica), altura da antena do ponto $\mathrm{B}(0,000 \mathrm{~m})$, altura da antena nos pontos P1, P2, P3, P4 e P5 (2,500m), opção de correção da ionosfera (Sim) e forma de seleção do satélite de referência (satélite mais alto). O processamento dos dados para a obtenção das coordenadas geocêntricas dos pontos da poligonal foi realizado com arquivos de dados correspondentes ao tempo de ocupação de 30 , 15,10 e 5 minutos em cada ponto.

O programa de processamento dos dados fornece as coordenadas geocêntricas tridimensionais (X, Y e Z ou h), referidas ao WGS 84. As coordenadas no sistema global dos pontos da poligonal, para cada tempo de ocupação de 30, 15, 10 e 5 minutos, foram transformadas para um sistema de coordenadas com referência local, para serem comparadas com as coordenadas da poligonal teste.

\section{Cálculo das coordenadas altimétricas no sistema topográfico local}

As coordenadas altimétricas ( $\mathrm{Z}$ ou $\mathrm{h})$ dos pontos referidas ao sistema WGS 84 foram transformadas para o sistema topográfico local, através de um procedimento descrito em HOFMANNWELLENHOF et al. (1997). Para atender esse objetivo, foi utilizada uma rotina computacional desenvolvida no Laboratório de Geomática do Dep. de Engenharia Rural da UFSM. Conhecidas as coordenadas geocêntricas tridimensionais ou elipsoidais $\left(\mathrm{X}_{0}, \mathrm{Y}_{0} \mathrm{e}\right.$ $\mathrm{Z}_{0}$ ) e as coordenadas geodésicas (latitude $/ \mathrm{j}_{0}$, longitude $/ \mathrm{l}_{0}$ e altitude $/ \mathrm{h}_{0}$ ) do ponto de referência (ponto B) e as coordenadas geocêntricas tridimensionais (X, $\mathrm{Y}$ e Z) dos pontos P1, P2, P3, P4 e P5, pode-se 
determinar a diferença de coordenadas geocêntricas (DX, DY e DZ) entre cada ponto e o ponto B. A rotina calcula a diferença de altura geométrica $(\mathrm{Dh})$ de cada ponto considerado com a base e as coordenadas $(\mathrm{Cx}$, $\mathrm{Cy}$ e $\mathrm{Cz}$ ) dos pontos no sistema local, referidas a mesma origem da poligonal em estudo.

Para cada tempo de ocupação nos pontos (30, 15, 10 e 5 minutos), foi obtida uma planilha de dados, reconstituídos a partir dos cálculos efetuados com base nos resultados obtidos através do levantamento com os receptores GPS. Os dados utilizados para comparação foram: as altitudes ortométricas $(\mathrm{H})$ e as diferenças de nível entre os pontos da poligonal.

\section{RESULTADOS E DISCUSSÃO}

Diferenças das altitudes geométricas (Dh) dos cinco pontos da poligonal nos diferentes tempos de ocupação dos pontos (30, 15, 10 e 5 minutos).

A tabela 1 mostra as diferenças nas altitudes geométricas, pontos da poligonal (P1, P2, P3, P4 e P5) nos tempos de ocupação de $30,15,10$ e 5 minutos, bem como os valores médios obtidos e seus respectivos desvios padrão, em relação à altitude geométrica da estação base, cujo valor utilizado foi de $129,0373 \mathrm{~m}$. Esses valores foram obtidos a partir dos dados fornecidos nos relatórios de saída do programa SPECTRUMSURVEY.

Os valores das diferenças de altitudes geométricas, mostrados na tabela 1, permitem observar que, em todos as situações, situam-se dentro do intervalo compreendido entre a sua média mais $2 \mathrm{~s} \mathrm{e}$ sua média menos $2 \mathrm{~s}$ o que indica que os resultados

Tabela 1 - Diferenças de altitudes geométricas $(\Delta \mathrm{h})$, entre a estação base (Ponto B) e os pontos da poligonal e ondulações geoidais $(\mathrm{N})$, em metros, nos diferentes tempos de ocupação (T), em minutos.

\begin{tabular}{lccccc}
\hline $\mathrm{T}$ & $\mathrm{P} 1$ & $\mathrm{P} 2$ & $\mathrm{P} 3$ & $\mathrm{P} 4$ & $\mathrm{P} 5$ \\
\hline 30 & $-17,839$ & $-14,316$ & $-22,385$ & $-15,823$ & $-16,312$ \\
15 & $-17,843$ & $-14,319$ & $-22,366$ & $-15,821$ & $-16,318$ \\
10 & $-17,833$ & $-14,317$ & $-22,464$ & $-15,824$ & $-16,545$ \\
5 & $-17,823$ & $-14,184$ & $-22,463$ & $-16,120$ & $-16,328$ \\
Média & $-17,834$ & $-14,284$ & $-22,419$ & $-15,897$ & $-16,376$ \\
$\sigma$ & 0,009 & 0,067 & 0,051 & 0,149 & 0,113 \\
$\mathrm{~T}$ & $\mathrm{P} 1$ & $\mathrm{P} 2$ & $\mathrm{P} 3$ & $\mathrm{P} 4$ & $\mathrm{P} 5$ \\
30 & 8,867 & 8,911 & 8,911 & 8,888 & 8,915 \\
15 & 8,863 & 8,907 & 8,931 & 8,890 & 8,909 \\
10 & 8,872 & 8,909 & 8,832 & 8,887 & 8,683 \\
5 & 8,883 & 9,042 & 8,833 & 8,591 & 8,899 \\
Média & 8,871 & 8,942 & 8,877 & 8,814 & 8,852 \\
$\sigma$ & 0,009 & 0,067 & 0,052 & 0,149 & 0,113 \\
\hline
\end{tabular}

não diferem estatisticamente com $95 \%$ de probabilidade. Dentre as altitudes geométricas determinadas para cada ponto da poligonal, observase que o ponto P4 apresentou a maior amplitude de variação, a qual pode ser confirmada pelo valor do desvio padrão encontrado $(\mathrm{s}=0,149 \mathrm{~m})$, em seguida vêm os pontos P5, P2, P3 e P1.

\section{Projeções em x e y entre a estação base e os pontos da poligonal.}

A tabela 2 mostra as projeções em x e y dos alinhamentos formados entre os diferentes pontos da poligonal e a estação base (Ponto B), em relação ao eixo x e y, nos diferentes tempos de ocupação, bem como os valores médios obtidos e seus respectivos desvios padrão.

As projeções em $\mathrm{x}(\mathrm{Px})$ dos cinco pontos da poligonal, apresentadas na tabela 2 , permitem observar que, para os diferentes tempos de ocupação, os valores obtidos situam-se dentro do intervalo compreendido entre a sua média $\pm 2 \mathrm{~s}$, indicando que os resultados não diferem estatisticamente para $95 \%$ de probabilidade. A maior amplitude de variação entre os diferentes tempos de ocupação foi observada no ponto P5, no qual o valor do desvio padrão foi igual a 0,220 $\mathrm{m}$. Analisando as projeções em y (Py), observa-se que, para todas situações apresentadas, os resultados situam-se dentro do intervalo compreendido entre a sua média $\pm 2 \mathrm{~s}$, indicando que os resultados não diferem estatisticamente para $95 \%$ de probabilidade. Nas projeções y (Py), a

Tabela 2 - Projeções em x (Px) e y (Py), em metros, dos alinhamentos formados entre a estação base e os pontos da poligonal nos diferentes tempos de ocupação (T), em minutos.

\begin{tabular}{lccccc}
\hline $\mathrm{T}$ & $\mathrm{P} 1$ & $\mathrm{P} 2$ & $\mathrm{P} 3$ & $\mathrm{P} 4$ & $\mathrm{P} 5$ \\
\hline & & \multicolumn{5}{c}{$\mathrm{Px}$} \\
30 & 717,820 & 516,005 & 290,414 & 383,530 & 678,731 \\
15 & 717,878 & 516,007 & 290,413 & 383,529 & 678,691 \\
10 & 717,873 & 516,004 & 290,173 & 383,530 & 679,144 \\
5 & 717,868 & 515,971 & 289,996 & 383,665 & 678,693 \\
Média & 717,860 & 515,997 & 290,249 & 383,563 & 678,815 \\
$\sigma$ & 0,029 & 0,017 & 0,203 & 0,068 & 0,220 \\
& & & & & \\
30 & 363,840 & 371,975 & 114,185 & $-222,305$ & $-55,846$ \\
15 & 363,860 & 371,975 & 114,190 & $-222,305$ & $-55,850$ \\
10 & 363,860 & 371,975 & 113,996 & $-222,303$ & $-56,036$ \\
5 & 363,853 & 372,184 & 114,102 & $-222,240$ & $-55,850$ \\
Média & 363,853 & 372,027 & 114,118 & $-222,288$ & $-55,896$ \\
$\sigma$ & 0,009 & 0,104 & 0,091 & 0,032 & 0,094 \\
\hline
\end{tabular}


maior amplitude de variação entre os tempos de ocupação ocorreu no ponto $\mathrm{P} 2(\mathrm{~s}=0,104 \mathrm{~m})$, seguido de P5, P3, P4 e P1.

\section{Modelagem da ondulação geoidal (N)}

A tabela 1 mostra as ondulações geoidais (N) dos pontos da poligonal, nos diferentes tempos de ocupação, bem como os valores médios obtidos e seus respectivos desvios padrão. Os valores da ondulação geoidal $(\mathrm{N})$ foram calculados a partir da equação $\mathrm{N}=129,0373-16,9248-\mathrm{Dh}-\mathrm{H}$, onde: $129,0373 \mathrm{~m}$ é a altura geométrica (h) da estação base; $16,9248 \mathrm{~m}$ o valor da altura da antena em relação ao marco $1792 \mathrm{H}$ da Rede Brasileira de Nivelamento; Dh a diferença de altitude geométrica de cada ponto da poligonal levantada com GPS (Tabela 1) e H refere-se às altitudes ortométricas dos pontos da poligonal teste (PGT). Os valores das ondulações geoidais, mostrados na tabela 1 , permitem observar que todas as situações situam-se dentro do intervalo compreendido entre a sua média $\pm 2 \mathrm{~s}$, o que indica que os resultados, não diferem estatisticamente, com mais de $95 \%$ de probabilidade. Observa-se que, no ponto $\mathrm{P} 4$, as ondulações geoidais apresentaram maior amplitude de variação $(\mathrm{s}=0.149 \mathrm{~m})$. Com os valores médios de ondulação geoidal (Tabela 1) e as médias das projeções em x e em y, dos pontos $\mathrm{P} 1, \mathrm{P} 2$, P3, P4 e P5, que constam na tabela 2, foram determinados os coeficientes do modelo de cálculo da ondulação geoidal (N), em função das coordenadas dos pontos da poligonal. O modelo matemático obtido foi de tipo: $\mathrm{N}=\mathrm{K}_{0}+\mathrm{K} \mathrm{Cx}+\mathrm{K}_{2} \mathrm{Cy}$, onde o valor de $\mathrm{K}_{0}$ é igual a 8,8371, o valor de $\mathrm{K}_{1}$ é igual a $3,818153 \times 10^{-5}$ e o valor de $\mathrm{K}_{2}$ é igual a $9,891581 \times 10^{-5}$, sendo $\mathrm{N}$ a ondulação geoidal em metros, expressa em função das coordenadas $\mathrm{Cx}$ e Cy dos pontos em relação à estação base. Os valores de $\mathrm{K}_{0}, \mathrm{~K}_{1}$ e $\mathrm{K}_{2}$ foram obtidos através de uma rotina computacional desenvolvida no laboratório de Geomática do Dep. de Engenharia Rural da UFSM.

\section{Coordenadas altimétricas $(\mathrm{H}$ ou $\mathbf{C z})$}

A tabela 1 mostra os valores da altitude ortométrica $(\mathrm{H})$ dos pontos da poligonal determinados por nivelamento trigonométrico e os valores da altitude ortométrica dos pontos da poligonal, calculados a partir dos dados obtidos através do levantamento com GPS, nos diferentes tempos de ocupação dos pontos. Os valores das altitudes ortométricas determinados a partir das altitudes geométricas obtidas com GPS foram calculados através dos dados fornecidos pelo processamento dos dados e do modelo geoidal determinados para a área em estudo, através da equação: $\mathrm{H}=\mathrm{H}+\mathrm{Dh}-\mathrm{K} . \mathrm{Cx}-\mathrm{K}$.Cy, na qual o valor de $\mathrm{H}$ é igual $\mathrm{a}^{\mathrm{B}} 103,2754^{\mathrm{l}} \mathrm{m}$, o vălor de $\mathrm{K}$ é igual a $3,818^{8} 153 \times 10^{-5}$, o valor de $\mathrm{K}$ é igual a $9,891581 \times 10^{-5}$, o valor de $\mathrm{Dh}$ foi obtido na tabela 1 e os valores médios de Cx e Cy foram obtidos na tabela 2 (Px e Py). Analisando a tabela 3, verifica-se que, para todas as situações, as diferenças entre as altitudes ortométricas (H) do polígono teste (PGT) determinadas por nivelamento trigonométrico e as altitudes ortométricas (H) obtidas a partir das altitudes geométricas (h) usando GPS foram centimétricas. Observa-se que nos pontos $\mathrm{P} 2$ e P4, as diferenças entre as altitudes ortométricas (H) do PGT e GPS no tempo de ocupação de 5 minutos foram superiores às demais. Observandose a média das altitudes ortométricas $(\mathrm{H})$ do PGT e do GPS, verifica-se que a menor diferença ocorreu no tempo de ocupação de 10 minutos.

\section{CONCLUSÕES}

Com base nos resultados obtidos, pode-se concluir que, embora a literatura recomende um tempo de ocupação dos pontos de 30 minutos, para linhas de base curta (distância $<20 \mathrm{~km}$ entre estação base e pontos a determinar), com receptores de freqüência $1.575,42 \mathrm{MHz}$, este estudo demonstra que tempos menores de ocupação (15, 10 e 5 minutos), também são adequados para a obtenção de uma diferença

Tabela 3 - Altitudes ortométricas (H) determinadas no polígono teste (PGT) e com receptores GPS nos tempos de ocupação de 30 , 15, 10 e 5 minutos.

\begin{tabular}{|c|c|c|c|c|c|c|c|c|c|}
\hline \multirow{2}{*}{ V } & \multirow{2}{*}{$\mathrm{H}_{\mathrm{PGT}}$} & \multicolumn{8}{|c|}{$\mathrm{H}_{\mathrm{GPS}}$} \\
\hline & & $30^{\prime}$ & $\Delta_{30}$ & $15^{\prime}$ & $\Delta_{15}$ & $10^{\prime}$ & $\Delta_{10^{\prime \prime}}$ & 5 & $\Delta_{5}{ }^{\prime \prime}$ \\
\hline $\mathrm{P} 1$ & 85,407 & 85,374 & $-0,033$ & 85,370 & $-0,037$ & 85,379 & $-0,028$ & 85,390 & 0,017 \\
\hline $\mathrm{P} 2$ & 88,886 & 88,903 & 0,017 & 88,899 & 0,013 & 88,981 & 0,095 & 89,035 & 0,149 \\
\hline P3 & 80,816 & 80,868 & 0,052 & 80,888 & 0,072 & 80,789 & $-0,027$ & 80,790 & $-0,026$ \\
\hline $\mathrm{P} 4$ & 87,401 & 87,445 & $-0,044$ & 87,447 & $-0,046$ & 87,444 & $-0,043$ & 87,148 & $-0,253$ \\
\hline P5 & 86,885 & 86,943 & 0,058 & 86,937 & 0,062 & 86,711 & $-0,174$ & 86,928 & 0,043 \\
\hline $\mathrm{M}$ & 85,879 & 85,907 & 0,028 & 85,908 & 0,029 & 85,861 & $-0,018$ & 85,858 & $-0,021$ \\
\hline
\end{tabular}

Ciência Rural, v. 33, n. 4, jul-ago, 2003. 
centimétrica nas altitudes analisadas. Mesmo considerando a precisão dos métodos topográficos convencionais, este estudo demonstra a possibilidade da utilização do Sistema de Posicionamento Global (GPS) de forma precisa nos levantamentos altimétricos, desde que se efetue a modelagem da ondulação geoidal.

\section{REFERÊNCIAS BIBLIOGRÁFICAS}

BERALDO, P.; SOARES, S.M. GPS introdução e aplicações práticas. Brasília : Luana, 1995. 148p.

HOFMANN-WELLENHOF, B.; LICHTENEGGER H.; COLLINS J. Global positioning system: theory and practice. New York : Springer-Verlag Wien, 1997. 389p.
MEREGE FILHO, P. A confiabilidade de altitudes determinadas com GPS. Fator GIS. Revista do Geoprocessamento, Curitiba, n.03, p.16-17, 1993.

SOKKIA. Operator's Manual: GSS1A, GPS Survey Receiver. Lenexa, USA, 1999a. 5-5 "não-paginado".

SOKKIA. Spectrum Survey : reference manual. Lenexa, USA, 1999b. 7-1 "não-paginado".

TEIXEIRA, N. N.; FERREIRA, L. D. D.; GARNÉS, S., J. A. Carta geoidal de Belo Horizonte: fase preliminar. In: CONGRESSO BRASILEIRO DE CADASTRO TÉCNICO MUlTifinalitário, 5., 2000, Florianópolis. Anais... Florianópolis : CIASC, 2000. p.1-7.

TOPCON AMERICAN CORPORATION. TOPCON GPS Receivers- GP-R1, GP-R1D, GP-R1DP Version 7 A: Operating Manual. New Jersey, USA, 1993. $219 \mathrm{p}$ 